\title{
NOVAS FRONTEIRAS ESPACIAIS: HIBRIDIZAÇÃO ENTRE ARTE E ARQUITETURA DIGITAL
}

\author{
Fábio F. Lima ${ }^{1}$ \\ arqfabiolima@gmail.com
}

Resumo: Nas práticas expressivas contemporâneas diversas produções são enlaçadas em posicionamentos circunstanciais, promovendo novas estratégias formais e realizando simbioses espaciais, graças aos recursos da computação e dos processos típicos da arte em suas cadências múltiplas. Nesse contexto, viabilizam fortes tendências à execução de procedimentos limítrofes de enunciação, graças a processos generativos e estruturas algorítmicas das aplicações lógico-matemáticas, contendo princípios abstratos nos seus interiores capazes de promover novas geometrias fluidas e cujas superfícies suscitam aspectos naturais. Nesse território poético, os edifícios são esculturas modeladas com atributos plásticos.

Palavras-chave: arte digital, arquitetura, processos híbridos.

Abstract: Expressive practices in contemporary productions are entwined in many placements circumstantial, promoting new strategies and making formal symbioses spatial, through to the computing resources and processes typical of art in its multiple cadences. In this context, strong tendencies to enable implementation of procedures bordering the enunciation, through to the generative processes and structures algorithmic applications of logical-mathematical, containing abstract principles in its interiors that promote new geometries and fluid whose surfaces raises natural aspects. In this poetic territory, the buildings are modeled sculptures with attributes plastics.

Key words: digital art, architecture, hybrid processes.

\section{INTRODUÇÃO}

Um dos aspectos mais marcantes das produções arquitetônicas na contemporaneidade diz respeito a sua intensa variação de possibilidades, cujas naturezas não remetem a desígnios projetuais facilmente identificáveis. Como uma maneira de discorrer os desvios e movimentos híbridos das topologias no espaço, como um fenômeno turbulento, acarretando crises de desordem, instabilidade e descoberta, a idéia de fronteira é aqui utilizada como uma atitude de olhar para determinados limites tangíveis. Essa sugestão tem por intuito localizar certas

\footnotetext{
${ }^{1}$ Fábio F. Lima é graduado em Arquitetura e Urbanismo pela PUC-Goiás (2000) e mestre em Cultura Visual pela FAV-UFG (2006). É Doutorando em Arquitetura e Urbanismo no PPG - FAU/UNB. É professor assistente do Curso de Arquitetura e Urbanismo da FAV - UFG, com experiência na área de Design, Comunicação Visual e Projeto de Arquitetura. Atua nas áreas de criação de imagens infográficas, videográficas, websites e multimídia. 
experiências extremas, nascidas de sensibilidades renovadas e em alguns terrenos fronteiriços, periféricos ou descentralizados da arquitetura, cujas manifestações podem ser localizadas em diversas práticas expressivas da atualidade.

Essa fronteira constitui o limite de um sistema, cuja região adjacente permeia uma máxima palpável. Não pode ser entendida como mera divisão ou segmento, mas como a própria etimologia sugere: o que abre dianteiras está na frente (séc. XIII, do lat. frons) (CUNHA, 1982). Nos padrões da civilização, as fronteiras em geral são marcadas pelos lugares que metaforizam uma revolução tecnológica, em extensões e forças orientadas para seus limites, sendo fatores de integração constituídos em zonas de possíveis interpenetrações.

Nesse sentido, observamos uma possibilidade permutativa dos signos se deslocarem em territórios de fronteira ou de redes, presentes também num aspecto de representação de códigos à distância, e igualmente associados à extensão limítrofe. A arquitetura passa a ser cada vez mais integrada às experiências das linguagens, cujo aspecto tridimensional engloba o próprio homem, acobertando-o nas suas atividades e funções diárias. As fronteiras espaciais revelam como os diversos tipos de agenciamentos, as disposições das partes ou dos elementos se posicionam em circunstâncias extremas e a capacidade de corromper as rotinas já conhecidas, após a sua inserção em práticas computacionais.

Fazer chegar nesse limite implica em procurar continuamente novas relações espaciais e refutar procedimentos já conhecidos, numa demanda que não cessa novas aspirações. $O$ espaço propiciado pela computação possibilitou desenvolver inúmeras vertentes formais, nos mais variados aspectos topológicos imaginados, com grandes diferenças daquelas concebidas por meio de atividades e suportes tradicionais (PIAZZALUNGA, 2005). Desse modo, a forma tridimensional complexa não se exaure nunca e, as invenções revertem-se no desejo pelo inusitado, numa produção cada vez mais surpreendente.

Essas produções espaciais, ainda presentes num mundo sem gravidade (MACHADO, 1997), no limiar de suas raias podem suscitar relações a qualquer universo significante. Os exemplos podem ter fins interativos, on-line, nos jogos, nas intervenções urbanas, nos salões de arte e museus, etc. Mas podem ser estruturas para escopo de aprendizado, stand's experimentais, moradias provisórias, testes de montagem e materiais, de fachadas e volumes interativos ou transponíveis, de caráter permanente ou efêmero, etc. Os resultados podem ter tecnologia de ponta (sintéticos, desenvolvidos em laboratório, em pesquisa a nível molecular), mas também podem ser tradicionais, como forma de investigar o que está aparentemente esgotado. 
Não mais refém apenas da função prática ou utilitária, mas sim que essa utilidade sirva principalmente a desejos cujos ímpetos extrapolem o lugar-comum, as mais variadas manifestações sensíveis dialogam na contemporaneidade com o espaço arquitetônico. Há sempre uma dimensão plástica que não deve nunca ser negligenciada, e “... uma arte deveria se definir [...] por um conjunto de conceitos mais abstratos relacionados às atividades produtivas, ou por certa lógica de organização dos seus elementos significantes" (MACHADO, 2003:166).

Assim como se presentifica noutros processos artísticos há uma corrosão indefinida dos seus modelos, cujas características já não são possíveis de serem extraídas ou determinadas, sendo possível perceber apenas determinadas nuances, das visualidades permutativas cujos parâmetros até pouco tempo eram ficção científica no cinema; ou ainda das formas indetermináveis ou caóticas presente nas artes; e ainda, dos processos experimentais de ambientes com configurações excêntricas ou até surreais do design. Nesses aspectos, todos parecem requerer a evocação de certas realidades criativas que não cessam significados: “...no terreno da cultura, o que se 'imita’ ou se assimila não são os enunciados diretamente [...], mas estruturas abstratas, arranjos sintáticos, modos de selecionar e combinar" (MACHADO, 2003:69). A contínua possibilidade de explorar essas fronteiras faz com que haja novas inserções, novas regiões adjacentes cujos contornos podem ser explorados. Especular as fronteiras possibilita rearticular e reorganizar aquilo que se encontra num terreno confortável, normalmente produzido como repetição estereotipada.

Nesse momento, talvez a arquitetura esteja presente no interstício que poderíamos compreender como extensão proveniente da cultura digital e a sua natureza matérica. Isso implica em dizer que praticamente vem se esgotando aquilo que não pode ser construído fisicamente, uma vez concebido no espaço virtual do computador. Além disso, ao comportar uma manifestação tridimensional, a obra abrange as dimensões humanas e, desse modo, talvez mais ampla e complexa que as demais artes visuais. Por meio das suas conexões espaciais, as dimensões e as demais noções de escala tomam aspecto fundamental e promovem a inserção das demais artes no seu próprio corpo, requerendo um diálogo mais amplo e complexo.

\section{AS FRONTEIRAS HIBRIDIZADAS}

O panorama expandido da arquitetura em suas fronteiras implica em observar os seus deslocamentos nas atividades principalmente que supõem a criação de estados sensíveis ou 
estéticos. Esses desvios relacionam-se às fronteiras compartilhadas que tanto promovem novas estratégias formais anteriormente não desenvolvidas como também trazem nas simbioses espaciais os recursos da computação e dos processos típicos da arte em suas cadências múltiplas. Com recursos de grande maleabilidade, a partir das suas instaurações no espaço virtual, são capazes de romper a iconicidade das representações estáticas (PIAZZALUNGA, 2005) e de sofrerem inúmeros tipos de controle, garantindo múltiplas propriedades plásticas, muito além daquelas aferidas noutros suportes.

As fronteiras arquitetônicas evidenciam as transformações e as interconexões num ambiente criativo, não expresso apenas no código digital, mas num modo de proceder artístico. Na investigação de fenômenos sígnicos híbridos é fundamental considerar os tipos de sintaxes encontradas, conseguindo explorar outras intensidades que as formas podem ocasionar. Nesse sentido, o termo grego hýbris (CUNHA, 1982) que caracteriza a resultante do cruzamento de espécies diferentes e que se afasta das leis naturais, é compreendido no que diz respeito às novas combinações de técnicas por diferentes vias de experimentação.

Nesses exercícios, as práticas de produção espacial se aproximam cada vez mais dos territórios poéticos, vinculados por uma linguagem arquitetural segundo lógicas espaciais nas suas fronteiras, ou dos seus procedimentos limítrofes de enunciação. Os dados digitais podem se metamorfosear indefinidamente e são transpostos em etapas de validação de caracteres muito distintos. Uma elaboração possível de processamento computacional pode se converter em entidades que no meio analógico, por exemplo, seria impossível (MACHADO, 1997). Esse reino digital é, a caráter, o lugar privilegiado para a manipulação circunstancial, e nessas prospecções, recorrerem a estágios de validação dessas formas, ao tratar da visibilidade da expressão lógico-numérica.

As formas tridimensionais geridas virtualmente constituem atualizações das chamadas imagens de síntese, confluências das abstrações matemáticas tornadas modelos sensíveis, aprazíveis segundo nossos sentidos. E “...estas ‘imagens’ tornadas visíveis não esgotam imediatamente a substância dos modelos formais que as engendram: só dão conta deles de modo parcial e relativo. Enquanto 'imagens', elas não permitem entender o modelo abstrato que as originaram, mas abrem uma janela para ele" (QUÉAU, 1993:92).

O modelo é uma geratriz para infinitas imagens - por meio da interface são visualizados os milhões de pixels - sob quaisquer pontos de vista, reunindo ao amparo das etapas construtivas e detalhes processados pelas operações algorítmicas. No que se refere às funções e ao programa “... a imagem é uma abstração baseada na estrutura biomórfica da 
concretização. A legitimação científica de uma imagem é especialmente o resultado de uma analogia algorítmica com princípios naturais de evolução" (GRAU, 2009:256). De tal modo que os algoritmos podem requerer um tempo muito grande ao serem expressos nas suas aparências imagos-volumétricas. No entanto, isso não implica em dizer que se abastecem de uma complexidade infinita; ao contrário, podem se considerados simples quando exibem os mesmos padrões em mudanças graduais de escala: um algoritmo do tipo fractal, por exemplo, muito provavelmente será compacto, com regras muito simples capazes de produzir uma grande complexidade.

\section{OS PROCESSOS GENERATIVOS}

Os resultados gerados por algoritmos que apresentam um desenvolvimento randômico e com certo grau de autonomia a partir de uma proposição compreendem estágios cujos princípios se dão no estabelecimento de regras e o domínio de determinadas técnicas, gerando uma imprevisibilidade no sistema. Talvez nesse aspecto, como ainda veremos adiante, pudéssemos considerar uma fronteira da radicalidade quanto aos problemas da criação, no que envolve uma linguagem e as suas atribuições de sentido. Há aqui um limiar, pois a partir da inserção de certas regras, o comportamento passa a conter uma autonomia, e não se podem prever exatamente seus desdobramentos, ainda que sejam traçadas algumas metas. Nas produções artísticas e, como veremos, nas aplicações dos espaços arquitetônicos, esse processo se mantém dentro de alguns parâmetros, de algumas demarcações, mas apresenta sempre um caráter de transição, podendo estar em níveis pequenos de detalhes ou possível de metamorfosear toda a estrutura macro de origem.

O processo generativo pode ser entendido como um método e as suas fases mais interessantes se concentram nos estágios processuais, dos que não se revertem apenas num resultado final, mas que se mantém em sucessão de estados transformativos. Como também num processo de elaboração poética, “... o cinetismo e a simultaneidade [...], com seus modelos combinatórios instáveis, [...] pressupõem uma sintaxe de deslocamentos, uma relação dinâmica de coerência, onde o sentido aparece como uma entidade em permanente devir" (MACHADO, 2003:220).

Nessas investidas, o processo tecnológico se apoia em exemplos naturais de deslocamentos graduais e progressivos, tais como as formações das nuvens, o crescimento das plantas, os movimentos das águas, as variações climáticas, etc. Todo um conjunto de dados 
parametrizáveis é observado como suporte inicial, do sistema que explora a alta complexidade nos seus componentes: fractais, mecânica dinâmica, redes neurais, algoritmos genéticos, comportamentos, etc., e tudo o que pode ser adaptado ao sistema.

Esse sistema complexo pode ser entendido como um conjunto de componentes pequenos capazes de interagir com uma das partes ou elementos do conjunto, nas suas adjacências e similares. A ação e reação entre os elementos são reconduzidas frequentemente e todo o conjunto se altera sem um agente específico externo ou sob uma hierarquia determinada. Pelas mudanças concomitantes nas suas diversas partes, há uma dinâmica relacional e, desse modo, um sistema que nunca atinge um aspecto de equilíbrio ou repouso, ainda que em sutis gradações, gera deslocamentos diversos e podem ser dados em diversas velocidades, observáveis ou não a olho nu.

O princípio do sistema é que para uma determinada ação ou alteração é necessário recompor a integridade daquele elemento, refazendo ou modificando outro aspecto no corpo do conjunto, ainda que se trate de uma extremidade. Dessa forma, numa sucessão em cadeia, as sequiências se ajustam em interações exponenciais. Novos feitios se desdobram sobre outros existentes e, a previsibilidade pode se tornar impossível: mínimos fatores podem mudar completamente o que se esperava e as informações serem redirecionadas.

Entre a ordem e desordem, ação e reação, os sistemas generativos se apoiam em instruções de adaptação e regulação. O importante é que deve haver certos níveis de complexidade contínua e estrutural para que tanto a ordem quanto a desordem coexistam, num modo discreto e contínuo e, a partir dessa relação se remeterem a um problema da entropia, pois no universo, há uma tendência maior das coisas se desorganizarem e tenderem ao caos.

Estando os níveis de automação dentro de certas regras, o acaso e a imprevisibilidade podem ser tomados em benefício a soluções espaciais inusitadas. A arte generativa advém dos sistemas computacionais que, por conseguinte, exploram o contexto das teorias complexas. Cada sistema contém seu nível de fatores intricados e, desse modo, scripts ou behaviors aparentemente simples podem ser desdobrados em resultados bastante complexos.

\section{ABSTRAÇÕES, GEOMETRIAS FLUIDAS}

Na qualidade de uma criação digital, as formas espaciais passam à exploração dos limites possíveis, formas que remetem por vezes, a um universo orgânico e procuram uma 
aparência associada ao natural, ao que representa um tipo de ordem espontânea para as coisas. Nesse contexto, viabilizam fortes tendências à execução das formas abstratas, das geometrias fluidas cujas superfícies suscitam movimentos naturais e que se esvaem, numa perspectiva de ordenação livre, como organismos capazes de se adequarem a terrenos irregulares ou instáveis. Se as estruturas algorítmicas são aplicações da lógica e da matemática, de princípios abstratos nos seus interiores, nada mais 'natural' que os resultados também o sejam. Apresentam assim, superfícies complexas cujos aspectos e propriedades simuladas seriam inconcebíveis sem o auxílio da máquina.
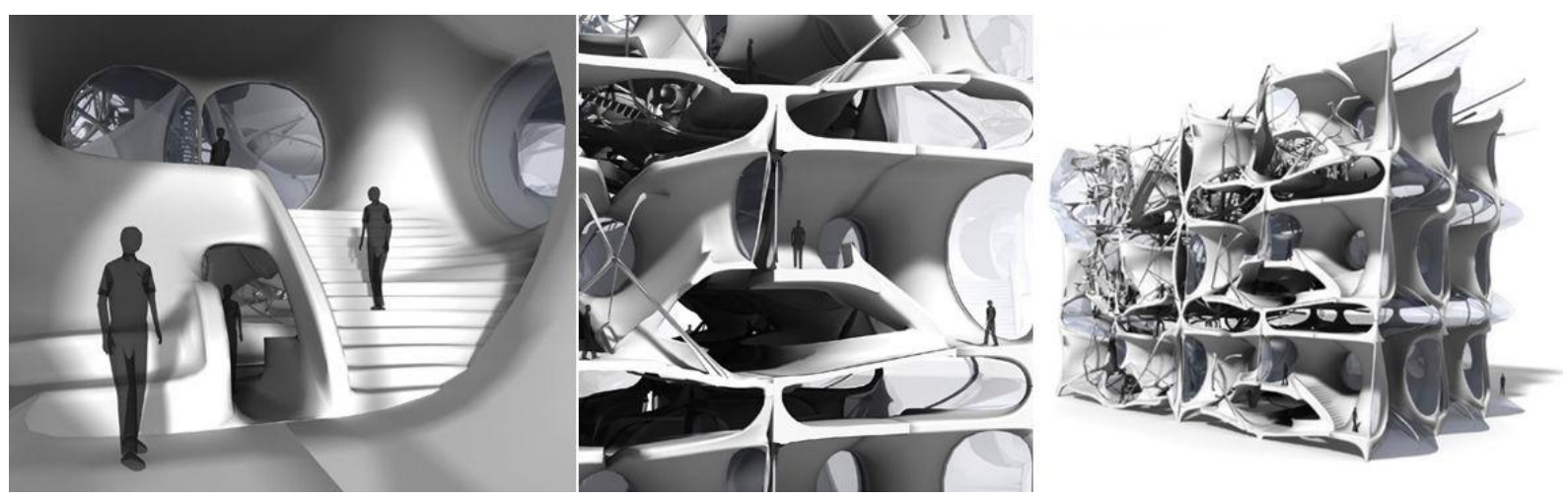

Fig. 01. Dubai Waterfront Hotel, Jerry Tate Architects, 2007.

Há vários designers e arquitetos com trabalhos nessas características, como Marcos Novak, Stephen Perrella, Lars Spuybroek, Greg Lynn, Kas Oosterhuis, Robert Neumayr, Bernhard Franken, NIO Architecten e outros. De forma geral, suas propostas incluem a fusão dos planos horizontais e verticais - não se distinguindo pisos das paredes - e os vãos para as aberturas são irregulares, adaptados a um recorte orgânico. A título de exemplo pode-se apresentar os projetos Dubai Waterfront Hotel, do grupo Jerry Tate Architects (ver Fig. 01) e Fibrous Tower do grupo Kokkugia (ver Fig. 02). Nessas propostas há uma elaboração geométrica minuciosamente aferida dentro dos parâmetros computacionais e, em ambas há fortes tendências conceituais cujas singularidades encontram amparo nos estudos da biomimética (bionics, biomimetics).

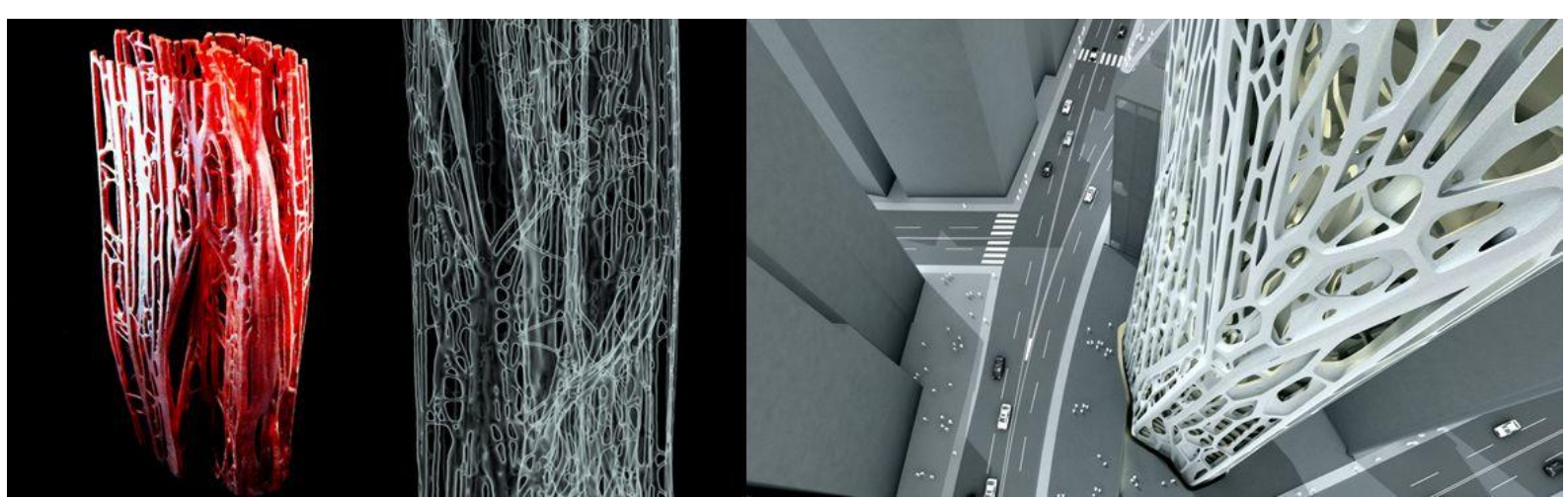


Fig.02. Fibrous Tower, Kokkugia, 2008.

Há um tipo específico de conhecimento com que determinadas "leis naturais" são traçadas, cuja ordem propicia aprender fenômenos aerodinâmicos, térmicos, óticos, estruturais, etc. Nesse sentido, as máquinas imitariam ou aplicariam essas características extraídas desses modelos biológicos - resignando-as em "homomorfo-homométricas" e "homológicas-projetivas" (HSUAN-AN, 2002). Dessa forma, os estudos concentram pesquisas sobre adaptações dos organismos ao meio, resultando num design que possibilita maior desempenho e menor gasto de energia adequada a um tipo específico de lugar.

Em ambos os casos, o modelo simulado pelo computador, amparado pela interface de um software é capaz de reagir aos processos simulativos do ambiente, dentro desse espaço digital. Dados algorítmicos são inseridos de forma a problematizar respostas formais, limites que conferem um tipo de aspecto, ao traduzir as fórmulas exponenciais das correntes de vento, temperatura, umidade, etc., em superfícies com base no mundo natural.

Assim, é possível constatar que do ato de concepção ao resultado a ser construído, cujos graus de complexidade das formas pareceriam impossíveis a tão pouco tempo atrás, são criados programas e rotinas específicas paralelas, capazes de executarem tais tarefas e, desse modo, as respostas passam cada vez mais a serem geridas internamente - cálculos, detalhamentos, adequações de materiais, etc. Cada vez mais, tudo o que está na instância do virtual contém, ao mesmo tempo, faculdade em ser edificado: virtual é efetivamente a potência de existir (LÉVY, 1999). A forma é, simultaneamente, o continuum resultante para a composição das forças que proverão a estrutura e, portanto, a sua autoportabilidade.

Além disso, é possível observar que a abstração intermediada pelos meios digitais viabiliza um espaço de especulações, na qualidade de sua extensa maleabilidade e cuja mutação descrita pelas expressões matemáticas trouxeram igualmente um tipo de realidade palpável. "As imagens de síntese são essencialmente abstratas, apesar de oferecerem um aspecto material, visível” (QUÉAU, 1993:92). Como propriedade intrínseca da abstração há o aspecto inicial e discreto da matemática, vital e despojada das qualidades sensíveis primárias (forma, volume, transparência, peso, etc.). Outros atributos visuais somente serão incorporados posteriormente como camadas de operações cujos algoritmos incorporam tais cálculos.

É interessante salientar então que os trabalhos abrem-se segundo dois momentos de abstração: primeiro enquanto função matemática e função computacional e, segundo, como modelo que se atualiza por meio da interface e cujas propriedades sensíveis são flutuantes. 
Essa última caracterizada geralmente pela busca em romper com a mimese da realidade, em qualidades que intentam transcender as aparências vivificadas (MONTANER, 2002).

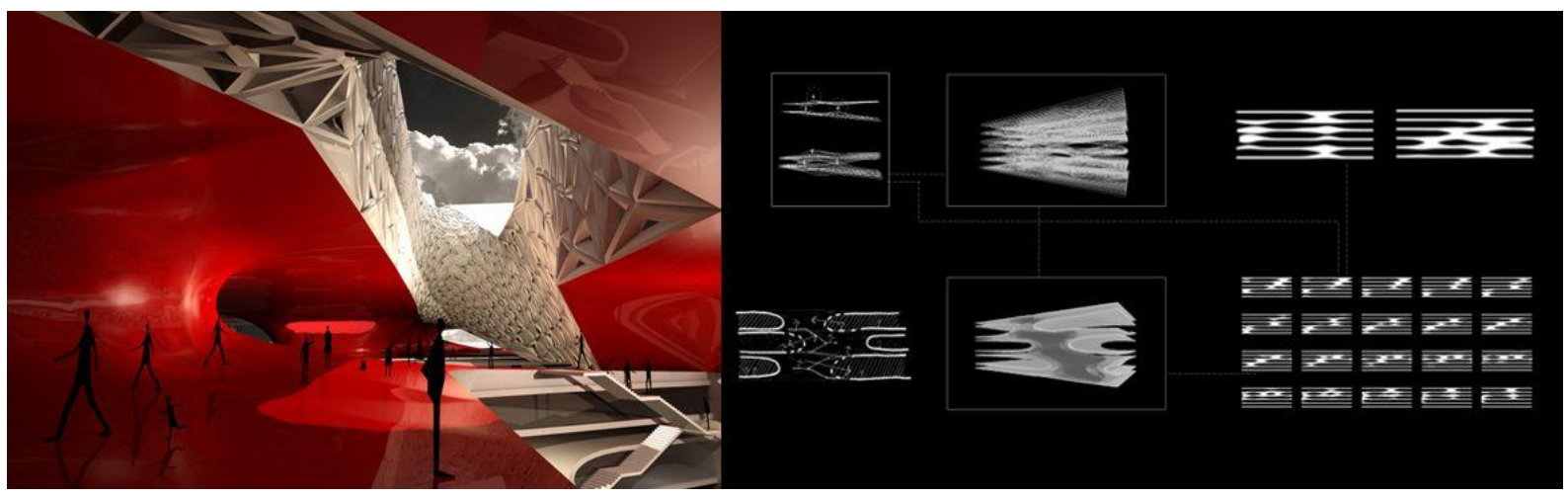

Fig.03. FTZ Athens, Kokkugia, 2006.

Deseja-se elaborar um objeto abstruso, cuja compreensão não passa pelas vias de uma referência similar. Muitos trabalhos seguem essas perspectivas, como as experiências com ambientes a partir de gráficos computacionais do grupo Kokkugia: Airbaltic Terminal, FTZ Athens (ver Fig. 03), Yeosu Pavilion, Swarm Urbanism, Taipei Performing Arts, etc. Ou do grupo Biothing: FissurePort, Phosphorescence, Bifid, aMaze, Invisibles, etc. Há também Rahim Ali e Hina Jamelle do Contemporary Architecture Practice, produzindo vários trabalhos importantes, como MoMA Summer Pavillion, Dubai Mixed-Up Tower, Reebok Flagship Store, etc. (ver Fig. 04).
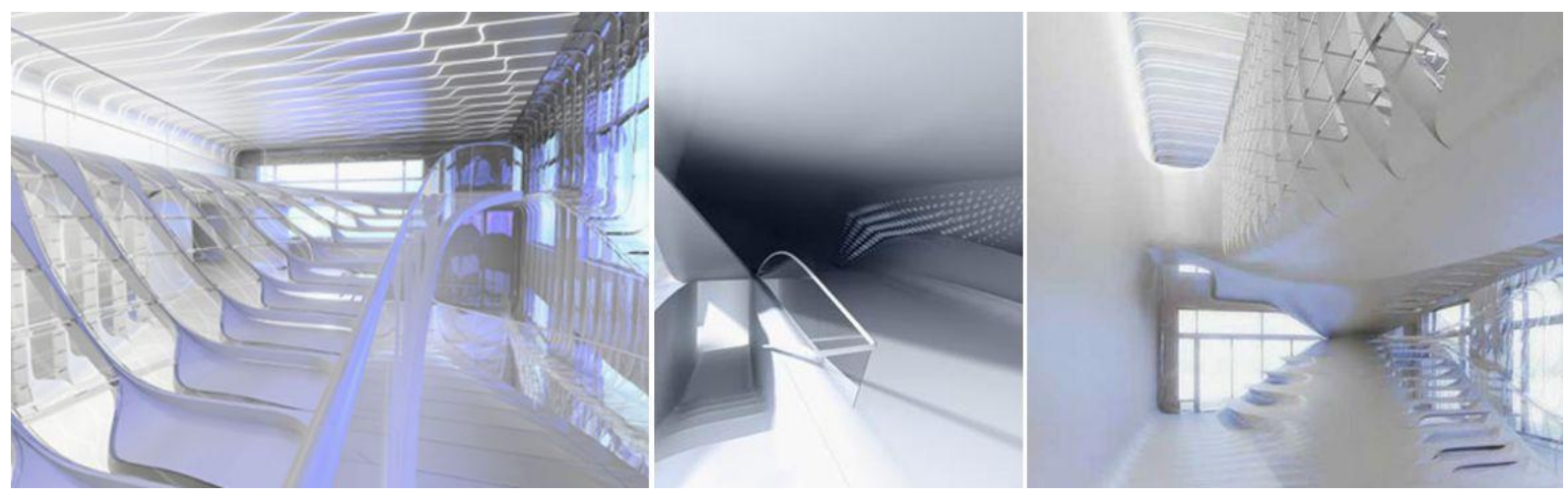

Fig.04. Reebok Flagship Store, Contemporary Architecture Practice, Shangai, 2005.

Essas arquiteturas digitais estabelecem relações junto às formas abstratas, e inquerem “... a emancipação da natureza, [...] a sobreposição de figuras, criando um novo tipo de transparência que não [é] literal, mas perceptiva e fenomenológica" (MONTANER, 2002:68). Não há intenção em imitar o mundo real, mas dispor relações formais (planos, superfícies, volumes que geram a realidade do objeto) adequadas a uma escultura espacial, modelada com atributos plásticos. E assim, “[...] uma das grandes proezas da computação é a sua 
potencialidade para dar uma dimensão concreta ao universo de pura abstração, [...] o seu poder de tornar sensível o formal” (MACHADO, 1997:146).
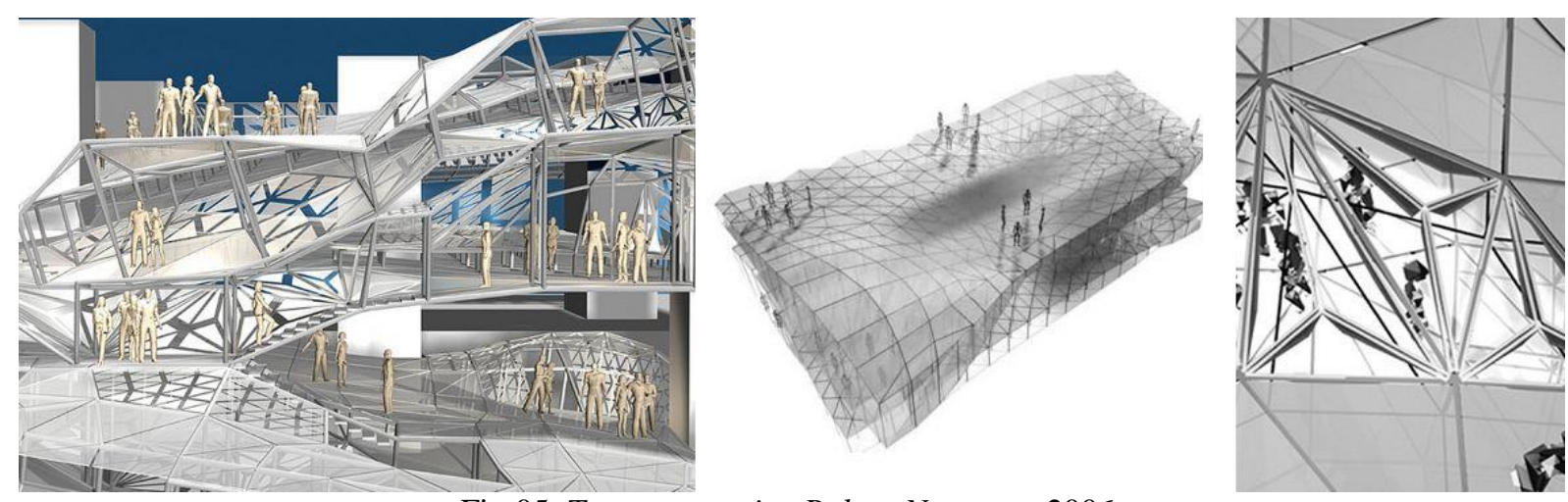

Fig.05. Topotransegrity, Robert Neumayr, 2006.

Há exemplos mais audaciosos, como o caso de Topotransegrity de Robert Neumayr (ver Fig. 05) cuja proposta de espaço público interativo torna a própria arquitetura uma espécie de interface computacional, um complexo sistema integrado capaz de conectar espaços, usuários e processos de desempenho em tempo real. Topotransegrity é uma enorme estrutura cinética que amplia constantemente suas imediações, realizando novas adaptações formais. A estrutura é capaz de realizar várias transformações, desde a superfície dotada de pequenas articulações nas partes inferiores e portanto adequadas a realizar recintos temporários até o estrato superior, suscetível de gerar extensões em aclives ou declives. Sensores, dispositivos de entrada e de redes sem fio são integrados para transformar o espaço arquitetônico em um sistema complexo interativo. Ainda que contenha uma multidão de usuários, a malha estrutural visa dar respostas em tempo real ao comportamento destes.

A estrutura é sintética, realizada com ligas leves e cujos materiais devem ser capazes de suportar flexões e estiramentos, respondendo aos movimentos dos transeuntes por meio de sensores adaptados que captam e fornecem informações em tempo real. A interface, nesse caso, está associada a um ambiente construído que, como um organismo, se adequa às mais diversas interveniências. Os dados são captados e convertidos no sistema como forma de um conflito que deve possibilitar uma resposta formal e conferir um aspecto.

\section{CONSIDERAÇÕES FINAIS}

Adquirindo extrema importância dentro desse novo contexto instaurado pelas vias virtuais, essas criações possibilitam constatar as arquiteturas como instrumentos para novas 
compreensões do nosso ambiente cultural contemporâneo. Além disso, essa prática se estabelece como crítica, refutando certa "lógica" instaurada no que se trata de um modo "adequado" de projetar, expandindo os níveis de raciocínio para além do que sozinho o projetista conseguiria alcançar. Muitas vezes resultantes de investigações inquiridoras e questionadoras do fazer arquitetônico, dirigem seus alvos às especificidades das estruturas compositivas de sentido e de efeitos sensíveis, desconstruindo a mera previsibilidade.

Cria-se uma ruptura com as tipologias, de forma que não manifeste um pensamento conivente às tradições formais / funcionais, mas sim dos aspectos conceituais, cuja declaração é a de não querer uma simples representatividade, mas algo que transcenda a sua própria aparência. Os trabalhos não possuem clara intenção em significar, mas antes, um jogo formal abstruso alheio à tradição. São revertidas em novos horizontes, não se apoiando em sistemas do passado como um tipo de movimento insurgente. As novas concepções não nascem por uma mera oposição a caracteres históricos, não se estruturam segundo um único aspecto nem a recursos estilísticos ou coisas do gênero; ao contrário, são oriundas de um campo muito específico, talvez mais próximas de circunstâncias adequadas às especificidades conceituais e que se possam aferir ensaios com diversos tipos de vieses ainda carentes de investigação. Mesmo ainda sendo um tipo de produção imaterial (em vias da existência física), subsiste através de um dispositivo que lhe dá visibilidade e vem a ser parte integrante dos sistemas metafóricos do nosso tempo, com que se pode elaborar aspectos ou contingências nas áreas do conhecimento para compreensão do nosso atual período histórico.

Dessa forma, a pergunta realizada por DERRIDA sobre "o que é o pensamento arquitetônico?" (2008:166) encontra fortes vazões nessas possibilidades digitais, carecendo de muitos exames e reflexões. As idéias mais básicas de "construir / arquitetar" são postas em dúvida: a dominação do espaço e a orientação sistemática já não são mais as premissas essenciais. Assim, é promovida uma conduta crítica para explorar a instabilidade, a incompletude, a imperfeição como modos válidos de se requerer um estado mais anímico para os desígnios projetuais, em aceitar o que não se pode dominar como algo inerente ao sistema. A arquitetura não precisa mais ser gerada por convenções estáticas de vistas planas ortogonais e a modelagem tridimensional pode ser obtida a partir de qualquer aspecto, inclusive de qualquer ordem dinâmica: das potências do movimento, da animação, das sucessões e dos processos de transformação gradual, das transições.

Enquanto campo constituído por definições distintas, essas novas vertentes parecem alvejar o cerne da episteme ( $\dot{\pi} \iota \sigma \tau \eta \dot{\mu \eta \eta})$ tectônica, resultando em enfrentamentos diretos aos 
conceitos existentes. Alguns dos problemas ocorrem pelo questionamento do conjunto de conhecimentos com vistas às suas explicações lógicas, materiais, técnicas, históricas, etc. Além disso, outro problema sublevado encontra-se nas questões de representação que, segundo MENEZES (2007), é uma operação pela qual a mente tem presente em si mesma uma imagem mental, uma idéia ou um conceito em correspondência a um objeto. Se supormos que o conhecimento é representativo e representar significa expor aquilo com que se conhece, nesse ambiente virtual instaura-se um problema porque essas faculdades não são colocadas de forma clara. Nesse contexto, a representação mental ou certos aspectos cognitivos seriam incapazes de alcançar os resultados aferidos pela máquina? Como forma de problematizar esses princípios tecnológicos, a forma pela qual se pensa, categoriza e valoriza a experiência também está sujeita à mudança nas mãos dessas mesmas tecnologias.

\section{REFERÊNCIA BIBLIOGRÁFICAS}

COOK, P. The paradox of contemporary architecture. Londres: John Wiley, 2001.

CUNHA, Antônio G. Dicionário etimológico nova fronteira da língua portuguesa. Rio de Janeiro: Nova Fronteira, 1982.

DERRIDA, Jacques. Uma arquitetura onde o desejo pode morar (entrevista a Eva Meyer). In: NESBITT, Kate (org.). Uma nova agenda para a arquitetura: antologia teórica (19651995). Trad. Vera Pereira. São Paulo: Cosac Naify, 2008.

GIANNETTI, Claudia. Estética digital: sintopia da arte, a ciência e a tecnologia. Trad. Maria Angélica Melendi. Belo Horizonte: C/Arte, 2006.

GRAU, Oliver. Lembrem a fantasmagoria! Política da ilusão do século XVIII e sua vida após a morte multimídia. In: DOMINGUES, Diana (org.), Arte, ciência e tecnologia: passado, presente e desafios. São Paulo: Ed. UNESP, 2009.

HSUAN-AN, Tai. Sementes do cerrado e design contemporâneo. Goiânia: Ed. da UCG, 2002.

LÉVY, Pierre. Cibercultura. Trad. Carlos Irineu da Costa. São Paulo: Ed. 34, 1999.

MACHADO, Arlindo. Máquina e Imaginário. São Paulo: Senac, 2000.

MENEZES, Alexandre M. Percepção, memória e criatividade em arquitetura. Belo Horizonte: Cadernos de Arquitetura e Urbanismo, v.14, n.15, 2007. 
MONTANER, Josep M. As formas do século XX. Trad. Maria Luiza Tristão de Araújo. Gustavo Gili: Barcelona, 2002.

OXMAN, Rivka. Digital architecture as a challenge for design pedagogy: teory, knowledge, models and médium. Technion, Institute of Technology, Haifa, Israel, 2008.

PIAZZALUNGA, Renata. A virtualização da arquitetura. Campinas, SP: Papirus, 2005. QUÉAU, Philippe. O tempo do virtual. In: PARENTE, André (org.), Imagem-máquina: a era das tecnologias do virtual. Trad. Rogério Luz et alii. Rio de Janeiro: Ed. 34, 1993.

ROCHA, Cleomar. Estéticas tecnológicas e interfaces computacionais. In: $7^{\circ}$ Encontro Internacional de Arte e Tecnologia. Brasília: UNB, 2008.

\section{SITES VISITADOS}

http://www.kokkugia.com/ (acesso em 02/02/2011).

http://www.biothing.org (acesso em 02/02/2011).

http://www.c-a-p.net/ (acesso em 02/02/2011).

http://www.5subzero.at/stuff/topotransegrity.html (acesso em 02/02/2011). 